\title{
Chemically Modified Coconut Shell Biochar for Removal of Heavy Metals from Aqueous Solution
}

\author{
Muhammad Imran-Shaukat ${ }^{1, a}$, Nur Rafikah binti Rosli ${ }^{1, b}$, Rafeah Wahi ${ }^{1, c^{*}}$, \\ Sharifah Mona Abd Aziz Abdullah ${ }^{2, d}$, Zainab Ngaini ${ }^{1, e}$ \\ ${ }^{1}$ Faculty of Resources Science and Technology, Universiti Malaysia Sarawak, 94300 Kota \\ Samarahan, Sarawak, Malaysia.
}

\author{
${ }^{2}$ Centre of Pre-University Studies, Universiti Malaysia Sarawak, 94300 Kota Samarahan, Sarawak, \\ Malaysia. \\ aimranchemi@gmail.com, bnurrafikahrosli@gmail.com, c*wrafeah@unimas.my, \\ daaasmona@unimas.my, enzainab@unimas.my
}

Keywords: adsorption, biochar, chemical modification, toxic heavy metals, wastewater treatment

\begin{abstract}
In this study, coconut shells were converted into biochar via pyrolysis and chemically modified via an acid-base treatment to enrich its adsorption capabilities. Batch experiments were carried out to analyze the adsorption potential of the modified coconut shell (MCSC) for removal of chromium, nickel, and copper from aqueous solution. The chemical modification increased the surface area of MCSC to $185.712 \mathrm{~m}^{2} / \mathrm{g}$. Batch adsorption study using MCSC resulted in $99 \%$ removal of copper, 95\% (nickel), and 39\% (chromium). The adsorption of studied metal ions fitted well with Langmuir isotherm, showing a monolayer adsorption process. A kinetic analysis showed that all the samples match a strong correlation coefficient in pseudo-second-order $\left(R^{2}>0.95\right)$, indicating the occurrence of a chemical adsorption process.
\end{abstract}

\section{Abbreviations}

CS: Coconut shell, CSC: carbonized Coconut shell- Biochar, MCSC: Modified carbonized Coconut shell- Modified Biochar.

\section{Introduction}

The rise in industrialization and urbanization has caused numerous environmental problems such as heavy metal pollutions. Large-scale emission of toxic metals is a matter of environmental and health concerns for humans, animals, and plants due to their toxicity. Heavy metal is toxic and tends to accumulate in organisms and cause sickness $[1,2]$. Heavy metals are considered inorganic waste which remains in the water system and not biodegradable. Among the common sources of these toxic heavy metals are electroplating, electronics, batteries, and metal treatment/fabrication [3].

Electroplating Industries produces large volumes of metal-rich effluents, which discharge several harmful substances including cyanides, cleaning agent, degreasing solvents, oil, fat, toxic heavy metals in particular chromium, nickel, and copper [2] in high concentrations [4] and exceed the permissible limits [5].

The successful removal of toxic heavy metals from effluent streams is of vital significance for freshwater reservoir safety. Numerous sophisticated methods were used to eradicate or mitigate the impacts of toxic heavy metals in waterborne industrial wastes, comprising of evaporation, coagulation, reverse osmosis, membrane filtration, chemical precipitation, chemical oxidation and reduction, advanced oxidation, ion exchange, electrochemical treatment, and adsorption. Adsorption is commonly accepted among these strategies due to operational simplicity, commercial affordability, and high throughput. Choosing an appropriate adsorbent is nonetheless crucial $[6,7,8,9,10]$. In recent times, Biochar used to be enshrined as an appropriate adsorbent for the multiplicity of ecological utilization and the researchers have had a big goal to eliminate have metals from wastewater. Biochar is a material rich in black, solid, durable, and porous carbon-rich substance with 